\title{
REVIEW
}

\section{Technical aspects of amyloid imaging for Alzheimer's disease}

\author{
Paul Edison*, Rainer Hinz² and David J Brooks ${ }^{1}$
}

\begin{abstract}
$\left[{ }^{11} \mathrm{C}\right]$ Pittsburgh Compound B positron emission tomography has now been extensively used to evaluate the amyloid load in different types of dementia and has become a powerful research tool in the field of neurodegenerative diseases. In the present short review we discuss the properties of amyloid imaging agent $\left[{ }^{11} \mathrm{C}\right]$ Pittsburgh Compound B, the different modalities of molecular imaging, image processing and data analysis, and newer amyloid imaging agents.
\end{abstract}

\section{Introduction}

Alzheimer's disease (AD) is the leading neurodegenerative disorder and accounts for approximately two-thirds of dementia. AD affects around $10 \%$ of people above the age of 75, and in the United States approximately 4 million people suffer from $\mathrm{AD}$-related dementia with annual associated costs estimated to be approximately $\$ 100$ billion.

The diagnosis of $\mathrm{AD}$ currently depends on patients having impairments in memory function and at least one other cognitive domain, to the extent that it impairs daily function. $\mathrm{AD}$ is a clinical diagnosis mainly based on NINCDS-ADRDA criteria [1] and DSM-IV criteria [2]. These criteria were revised recently by the international working group for new research criteria for the diagnosis of $\mathrm{AD}$ [3]. The cardinal features are late-onset impairment of short-term recall $[4,5]$ associated with deterioration of language and visuo-spatial functions $[6,7]$ in the absence of disturbance of consciousness and systemic disorders. A postmortem diagnosis of $\mathrm{AD}$ is based on the presence of extracellular senile plaques positive for $\beta$-amyloid protein $(\mathrm{A} \beta)$, dystrophic neurites, and intracellular

\footnotetext{
*Correspondence: paul.edison@imperial.ac.uk

'Medical Research Council Clinical Sciences Centre and Division of Neuroscience, Imperial College London, Cyclotron Building, Hammersmith Hospital, Du Cane Road, London W12 0NN, UK

Full list of author information is available at the end of the article
}

neurofibrillary tangles in the brain. Neurofibrillary tangles contain a hyperphosphorylated form of the microtubule-associated protein, tau, and also ubiquitin [8]. Amyloid plaques are composed of 40 to 42 amino acid $A \beta$-folded peptides. Two types of amyloid plaques are present in neurodegenerative diseases: one with a central core and radiating fibrils, the fibrillar amyloid; and second, the diffuse (amorphous) amyloid. A small degree of $\mathrm{AD}$-like pathology can be found in cognitively normal individuals over the age of 75 but large deposits of amyloid suggest $\mathrm{AD}$.

Until a few years ago, magnetic resonance imaging (MRI) and cerebral blood flow studies were the only methods by which we could gain information about the changes in the living human brain. Structural MRI and blood flow studies, however, depend on gross changes in brain structure and function that suggest gross atrophy or a functional alteration that has already occurred. These markers are thus secondary phenomena and are therefore not the primary targets for following patients over a period of time or for diagnosing very early and subtle changes. Clinico-pathological studies suggest that neuronal loss has already occurred by the time gross atrophy is detected by MRI. Positron emission tomography (PET) with $\left[{ }^{18} \mathrm{~F}\right]$ fluorodeoxyglucose adds to the diagnostic and prognostic accuracy in the clinical evaluation of $\mathrm{AD}$ [9], but the technique still detects an indirect measure of disease presence or progression.

Modification of the polar amyloid binding histological dye, thioflavin $\mathrm{T}$, led to the finding that neutral benzothiazoles bind to amyloid with high affinity and additionally cross the blood-brain barrier [10]. The benzothiazole amyloid binding agent 2-(4'-methyl-aminophenyl)-benzothiazole and related compounds bind to amyloid with low nanomolar affinity, enter the brain in amounts sufficient for imaging with PET and clear rapidly from normal brain tissue $[11,12]$. At the low nanomolar concentrations typically administered during PET studies, 2-(4'-methyl-amino-phenyl)-benzothiazole binds to extracellular amyloid plaques in postmortem brain slices but not to intracellular neurofibrillary tangles. In vitro studies suggest that, while 2-(4'-methyl-amino-phenyl)-benzothiazole binds to fibrillar $A \beta$ deposits found in the cortex 
and striatum, it does not bind to amorphous $A \beta$ deposits found in the cerebellum.

A hydroxylated derivative of benzothiazole, $\mathrm{N}$-methyl[11-C]2-(4'-methylaminophenyl)-6-hydroxybenzothiazole - widely known as $\left[{ }^{11} \mathrm{C}\right]$ Pittsburgh Compound $\mathrm{B}$ $\left(\left[{ }^{11} \mathrm{C}\right] \mathrm{PIB}\right)$ - has been synthesised as a PET tracer and studied in humans. An initial study showed that $\left[{ }^{11} \mathrm{C}\right] \mathrm{PIB}$ shows a significant uptake in AD subjects compared with the control subjects [13]. Following this initial study, several other studies have shown similar findings in $\mathrm{AD}$ and in other dementia [14-16]. Postmortem studies have shown a direct correlation between $A \beta$ plaque and in vivo $\left[{ }^{11} \mathrm{C}\right]$ PIB retention measured by PET imaging. Studies have shown that the fluorescent PIB analogue 6-CN-PIB labelled $A \beta$-containing structures, including compact/ cored, diffuse, neuritic and non-neuritic $A \beta$ plaques. 6-CN-PIB also labelled vascular amyloid, but no signal was detected in neurophil threads or dystrophic neurites and a signal was only detected sporadically on an extracellular ghost tangle. A patient who underwent postmortem neuropathological examinations 10 months after $\left[{ }^{11} \mathrm{C}\right]$ PIB PET imaging demonstrated that in vivo retention correlated directly with postmortem quantification of PIB and A $\beta$ plaque load but not with neurofibrillary tangle or other neurofibrillary pathology [17].

In the present article, a review of the technical aspects of amyloid imaging for $\mathrm{AD}$ will be presented. We therefore first introduce the general procedure for in vivo molecular imaging in man using PET. We then go on to describe image processing and data analysis.

\section{Molecular imaging in man}

The molecular imaging process is shown in Figure 1. In the first step (top right of the figure), radioisotopes are produced either in dedicated cyclotrons - for example, the positron emitters ${ }^{11} \mathrm{C}$ or ${ }^{18} \mathrm{~F}-$ or in special radionuclide generators - for example, the single-photon emitter ${ }^{99 \mathrm{~m}} \mathrm{Tc}$. After the production of the radioisotope, the radiolabelled compounds for the imaging study are produced in a radiochemistry system. Various routes for the radiochemistry usually exist; for example, for ${ }^{18} \mathrm{~F}$ labelled tracers by nucleophilic or electrophilic reaction. Quality control is performed to check and confirm that the radiopharmaceutical product is within predetermined specifications; for example, for specific activity, radiochemical purity or sterility.

The basis of tracer imaging is the detection by external devices of the radiation emitted from the radiolabel attached to the tracer injected into humans. In most cases, the nuclear disintegration of the radioisotope is detected via registering photons that are either uncorrelated (hence single-photon imaging) or that are paired as the result of positron annihilation. This imaging technique is then known as coincidence imaging or positron imaging, and is schematically shown in the scan box of Figure 1. A pair of photons resulting from the annihilation of a positron generated by the conversion of a proton in the nucleus is recorded as a line of response by the PET scanner. Tomographic image reconstruction techniques are subsequently employed to reconstruct a dynamic sequence of emission images from the brain scan [18]. Today, PET scanners operate in three-dimensional mode, covering the entire brain in a single scan with an axial field of view of at least $15 \mathrm{~cm}$. Modern PET scanners are usually combined PET/computer tomography systems as they include an integrated X-ray computer tomograph for the acquisition of photon attenuation images required for the correction of the PET images for the effects of photon attenuation and scatter. Combined PET and MRI systems are just emerging that combine the excellent contrast between grey and white matter provided by the magnetic resonance acquisition with the molecular images of the PET study.

The most widely used method for the reconstruction of quantitative brain images using PET is filtered back projection, an analytical image reconstruction method. Filtered back projection is computationally fast and has linear properties, which means the precision of the reconstructed images is independent of the location within the image and of the intensity of the object. Iterative image reconstruction, on the other hand, is computationally expensive and often only slowly converging and in an object-dependent manner. Iteratively reconstructed images are visually more appealing, because they do not exhibit the streak artefacts typical for filtered back projection reconstructed images. As the iterative image reconstruction allows one to more accurately model the entire imaging process, resolution effects can be included in the system description images with higher spatial resolution than those from filtered back projection can therefore be obtained.

The absolute quantification of the radiotracer kinetics in the tomographic images normally requires an input function. The input function is the time course of the radiotracer in the supply stream that drives the tissue response. The time course of the concentration of the radiolabelled compound in arterial plasma therefore has to be measured. In contrast to the acquisition of the images, which is performed by a single instrument (a SPECT or PET camera), the measurement of the plasma input function requires the combination of several laboratory devices. Online blood detector systems are used to provide whole blood activity measurements of continuously withdrawn blood with excellent temporal resolution but with limited sensitivity due to their relatively small counting volume. Well counters or automated gamma counters are used to measure with 


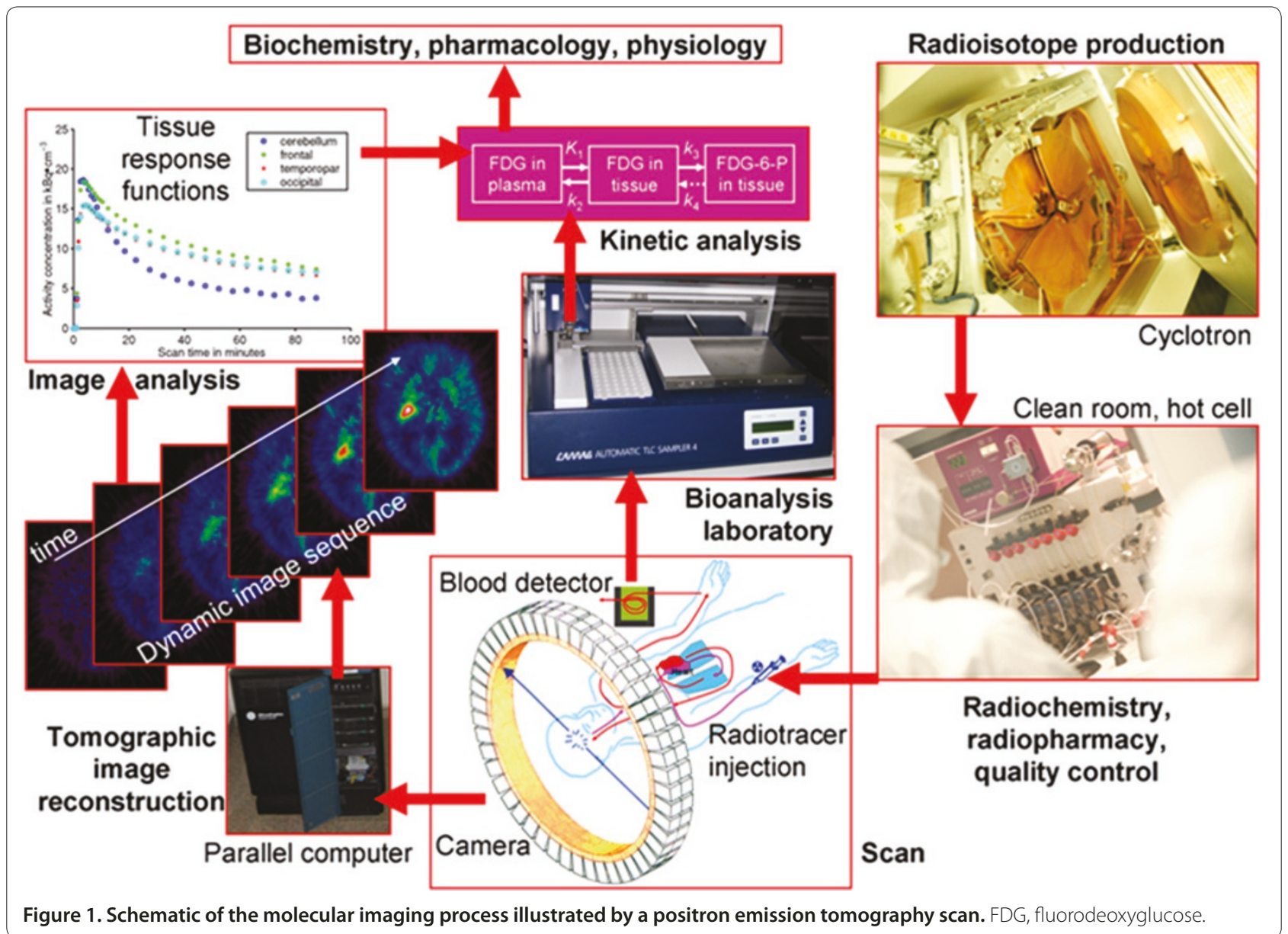

very high sensitivity the activity of discrete blood samples or, after centrifugation, of plasma samples. For radiotracers that undergo metabolism in the body, quantitative assays of the plasma samples to determine the fraction of radioactivity that is due to unmetabolised parent compound is required to obtain the input function. The laboratory setup for these analyses often involves solid-phase extraction followed by HPLC or thin-layer chromatography. Figure 2 shows an example chromatogram obtained from an HPLC analysis run of a scan with $\left[{ }^{11} \mathrm{C}\right] \mathrm{PIB}$.

\section{Image processing and data analysis}

After completion of the PET scan and the reconstruction of the dynamic images from the emission scan, an integral or sum image is generated in order to perform a co-registration with a structural volumetric magnetic resonance image as shown in Figure 3. This then allows the accurate definition of volumes of interest (VOIs) on the brain imaging data. Automated methods using atlases defined on brain templates are used as well as VOIs being manually outlined, particularly in cases with high levels of brain atrophy.
Using the set of VOIs defined, the dynamic PET images are then sampled and tissue time-activity curves generated. As is illustrated in Figure 4, these tissue timeactivity curves represent the measured activity concentration averaged across the VOI - which implies that, in the ensemble of volume elements (voxels) comprising a VOI, all voxels share the same parameters of the underlying physiological and biochemical processes, and only differ as they are different realisations of the same random process. This means that special attention has to be paid to tissue heterogeneity when VOIs are defined, and often magnetic resonance images segmented in different tissue classes (grey matter, white matter and cerebrospinal fluid) are employed for the definition of homogeneous VOIs. As an example, the difference in the $\left[{ }^{11} \mathrm{C}\right] \mathrm{PIB}$ signal between cerebellar grey matter and cerebellar white matter is highlighted in Figure 3.

The purpose of tracer kinetic analysis (centre top box in Figure 1) is to disentangle the different processes that jointly result in the tissue response curves obtained [19]. For amyloid imaging studies, the contributions to consider are as follows. First, tracer delivery and washout as the amyloid imaging markers currently used (for 


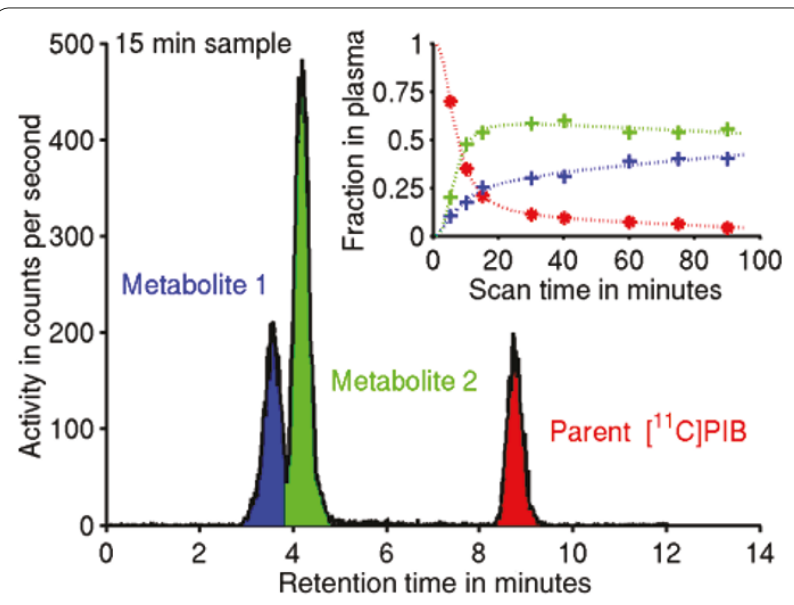

Figure 2. Analysis of radiolabelled metabolites in a plasma sample. Data from the 15-minute sample of a human subject injected with $370 \mathrm{MBq}\left[{ }^{11} \mathrm{C}\right]$ Pittsburgh Compound $\mathrm{B}\left(\left[{ }^{11} \mathrm{C}\right] \mathrm{PIB}\right)$, a marker of amyloid deposition in the brain. The plot shows the HPLC trace with three identifiable peaks. The peak of the unmetabolised parent compound with about a 9-minute retention time follows two more hydrophylic metabolites that partly overlap. Insert: measurements of the fractions of radioactivity in plasma belonging to metabolite 1, metabolite 2 and $\left[{ }^{11} \mathrm{C}\right] \mathrm{PIB}$, respectively. Eight plasma samples were analysed for this 90-minute positron emission tomography scan. The plot illustrates that the parent $\left[{ }^{11} \mathrm{C}\right] \mathrm{PIB}$ (red line) is rapidly metabolised in humans. Modified with permission from [42].

example, $\quad\left[{ }^{11} \mathrm{C}\right] \mathrm{PIB}, \quad\left[{ }^{18} \mathrm{~F}\right] \mathrm{FDDNP}, \quad\left[{ }^{11} \mathrm{C}\right] \mathrm{SB}-13, \quad\left[{ }^{18} \mathrm{~F}\right]$ BAY94-9172 and florbetapir $\left.\left(\left[{ }^{18} \mathrm{~F}\right] \mathrm{AV}-45\right)\right)$ are thought to cross the blood-brain barrier by passive diffusion, the delivery to and washout from brain tissue of these radiotracers is governed by cerebral blood flow. A second contribution is specific binding - the association, and dissociation for reversibly binding ligands, of the radioligand with the target (that is, $A \beta$ ). Another contribution is nonspecific binding - referring to any nonsaturable binding that occurs to other sites than $A \beta$ (for example, to membranes or lipid fractions). A fourth contribution is radiolabelled metabolites - several of the $\left[{ }^{18} \mathrm{~F}\right]$-labelled radiotracers used for amyloid imaging have been reported to form radiolabelled metabolites in vivo that are also able to cross the blood-brain barrier [20]; part of the radioactivity signal measured in brain tissue is therefore due to the contamination with radiolabelled metabolites. Finally, vascular activity - owing to the spatial resolution of the positron cameras of several millimetres, any VOI defined in the brain contains a few per cent blood volume; the spill in of activity from the vasculature therefore needs to be accounted for.

Using mathematical modelling and parameter estimation methods, system parameters such as rate constants, volumes of distribution or binding potentials [21] can be estimated from the dynamic imaging data. The outcome parameters chosen should, of all the contributions listed above, reflect the specific binding to the maximum possible extent and should be insensitive to the other confounders. For example, it has been shown for $\left[{ }^{11} \mathrm{C}\right] \mathrm{PIB}$ that the accumulation rate did not correlate with cerebral blood flow [22]. The parameter estimates can either be obtained regionally for each VOI, or they can be calculated for each voxel individually and then again represented as an image that is often referred to as a parametric map [23] (Figure 5). Parametric maps can then be interrogated for parameter changes that do not correspond to the anatomically predefined VOIs.

A variety of modelling approaches exists and they have been applied to amyloid imaging studies with $\left[{ }^{11} \mathrm{C}\right] \mathrm{PIB}$. These approaches range from compartmental models [24], through graphical analyses such as Logan plots [25] or Patlak plots [26,27], to spectral analysis [28] and reference tissue models $[29,30]$. In reference tissue models, the tissue time-activity curve of a region without specific binding is used as a substitute for the plasma

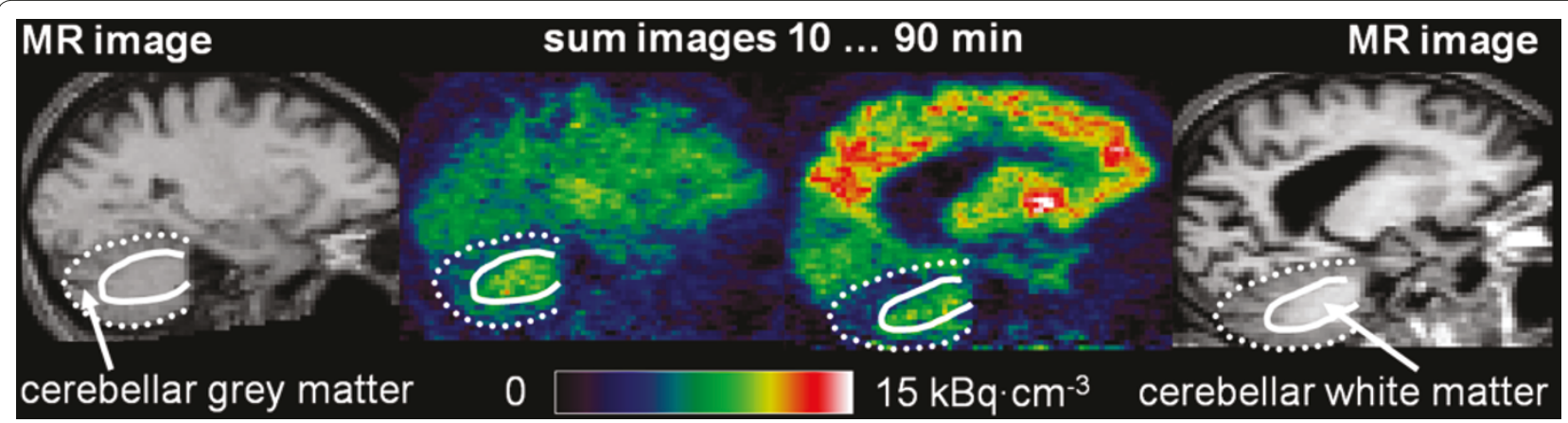

Figure 3. Sagittal image sections from a control subject and an Alzheimer's disease patient. Sagittal image sections from (left) a control subject and (right) an Alzheimer's disease (AD) patient. Positron emission tomography (PET) images (colour scale in the centre) were acquired in 90-minute scans after bolus injection of $370 \mathrm{MBq}\left[{ }^{[1} \mathrm{C}\right]$ Pittsburgh Compound $\mathrm{B}\left(\left[{ }^{11} \mathrm{C}\right] \mathrm{PIB}\right)$. The magnetic resonance (MR) images were co-registered to the PET images. Visual inspection reveals an increased uptake of [" $\left.{ }^{11} \mathrm{C}\right] \mathrm{PIB}$ in the cortical areas of the AD patient and no obvious difference in the cerebellum compared with the control subject. 

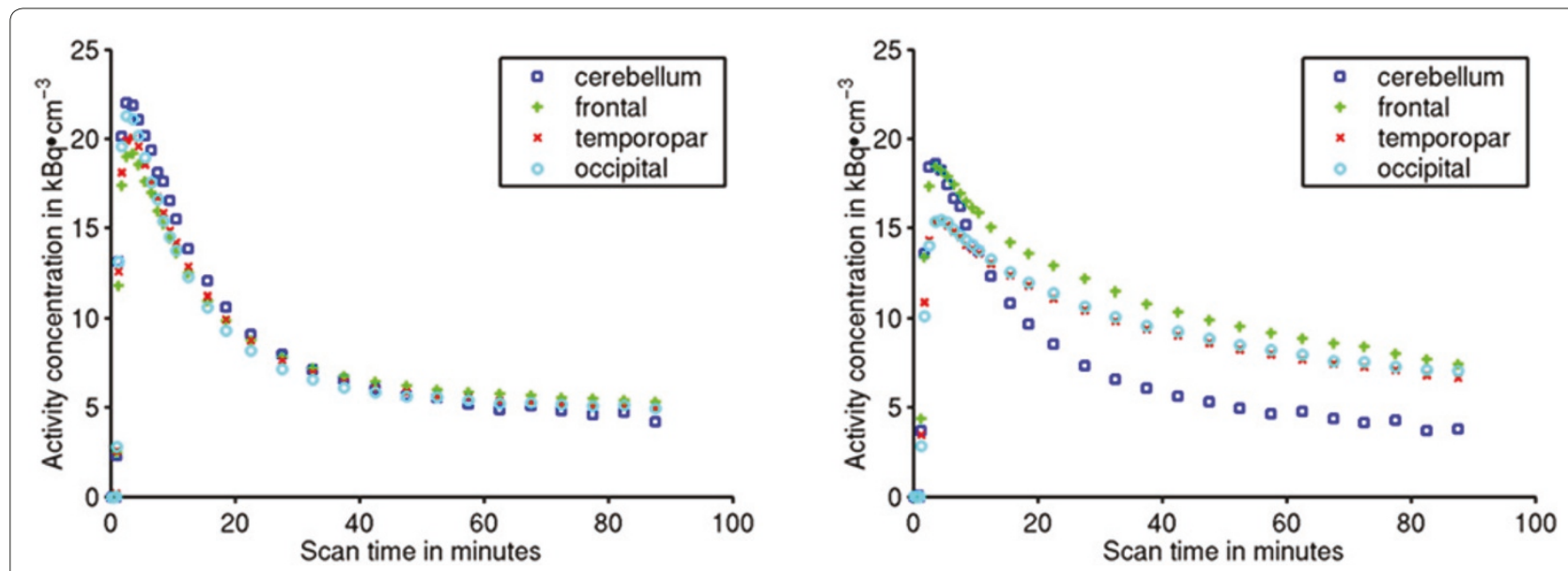

Figure 4. Tissue time-activity curves. Tissue time-activity curves (TACs) from the two subjects shown in Figure 3 for four regions: cerebellar grey matter (cerebellum), frontal cortex, temporoparietal cortex and occipital cortex. (Left) Age-matched control subject. (Right) Alzheimer's disease patient. TACs shown corrected for radioactive decay.

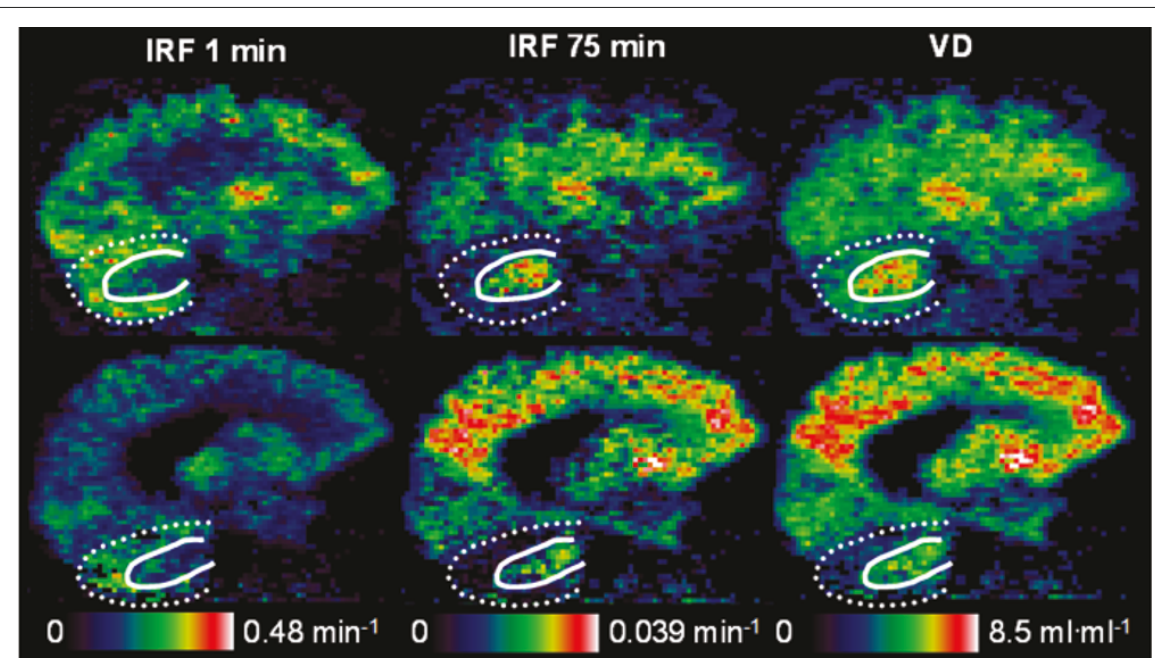

Figure 5. Parametric maps. Parametric images from the $\left[{ }^{11} \mathrm{C}\right]$ Pittsburgh Compound $B\left(\left[{ }^{11} \mathrm{C}\right] \mathrm{PIB}\right)$ scans of the two subjects shown in Figure 3 : top images, control subject; bottom images, Alzheimer's disease (AD) patient. Images generated with spectral analysis; colour bars for each column indicate the image minimum and maximum values. The impulse response function (IRF) at 1 minute in the left column gives a reflection of tracer delivery. The cerebral blood flow in most grey matter areas of the AD subject's brain is lower than that in the elderly control subject. The IRF 75-minute images in the centre give an indication of $\left[{ }^{11} \mathrm{C}\right] \mathrm{PIB}$ retention in tissue. In the control subject, $\left[{ }^{11} \mathrm{C}\right] \mathrm{PIB}$ is retained predominantly in the white matter; whereas in the AD patient, widespread [" $\mathrm{C}] \mathrm{PIB}$ retention in cortical grey matter occurred with association cortical areas, in particular, being targeted. Note that the cerebellar grey matter in both the control subject as well as the AD patient shows only very little $\left[{ }^{11} \mathrm{C}\right] \mathrm{PIB}$ retention. The total volume of distribution (VD) parametric images in the right column also reflect $\left[{ }^{11} \mathrm{C}\right] \mathrm{PIB}$ uptake in tissue, but with a slightly lower contrast between grey matter and white matter than the IRF 75-minute parametric images.

input function. For studies of sporadic AD the cerebellar grey matter is widely used as a reference region because postmortem investigations confirmed negligible concentrations of $A \beta$ in cerebellar grey matter in this disease. However, careful validation of the reference region is required for each disease population.

One of the commonly used methods of analysis is the target to cerebellar ratio, commonly referred to as the RATIO method. Different groups have used different time points to create RATIO images from 40 to
60 minutes, from 40 to 70 minutes and from 60 to 90 minutes. These different time points largely give comparable results, however - and at later time points, while the signal increases, the noise also increases. Again, in different studies, different RATIO values have used as cut-off points [31,32]. Some studies have used a strict cut-off value of two standard deviations above the control mean for individual regions, while other studies have used much more liberal cut-off values and a RATIO value of 1.4 or even 1.5. Even though different scanners differ 


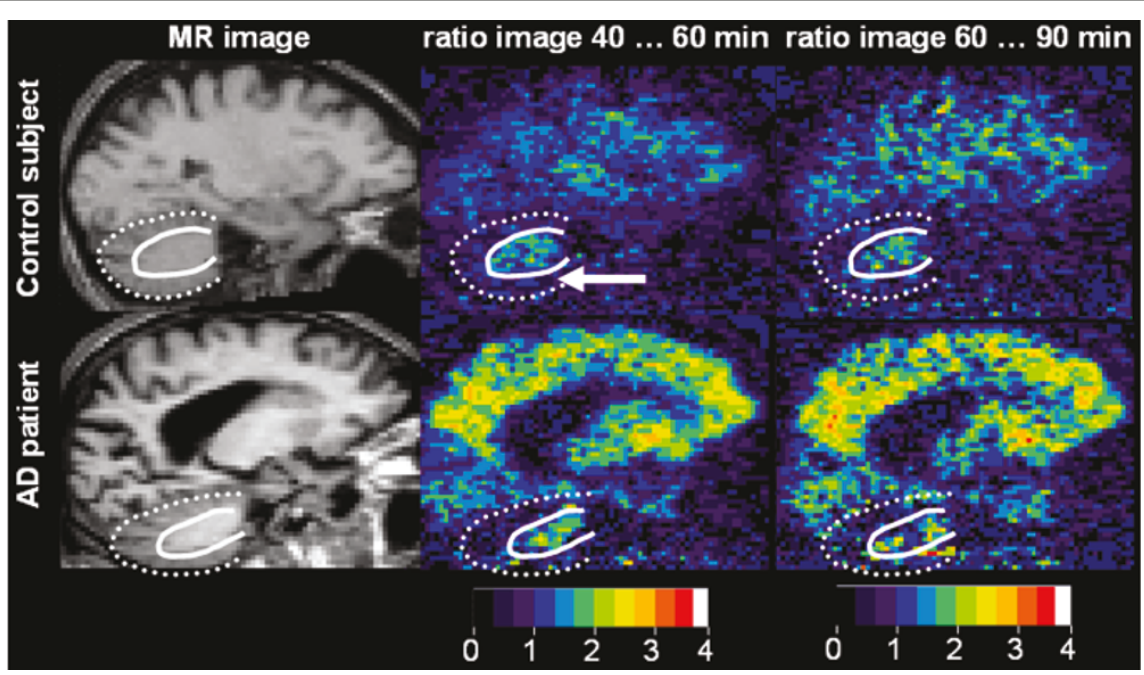

Figure 6. Ratio maps. Ratio images from the $\left[{ }^{11} \mathrm{C}\right]$ Pittsburgh Compound $\left.\mathrm{B}\left({ }^{11} \mathrm{C}\right] \mathrm{PIB}\right)$ scans of the two subjects shown in Figure 3 : top images, control subject; bottom images, Alzheimer's disease (AD) patient. Images generated by dividing the mean activity concentration of each voxel from 40 to 60 minutes post injection (centre) or from 60 to 90 minutes post injection (right) by the mean activity concentration of cerebellar grey matter (white arrow) of the same time interval. The $T_{1}$-weighted structural magnetic resonance (MR) images in the left column are shown for reference only. The colour bars at the bottom of the columns indicate the image minimum and maximum ratios. A visual comparison with the 10 to 90 minute sum images shown in Figure 3 immediately reveals the much higher levels of image noise in these late images due to the ${ }^{11} \mathrm{C}$ half-life of 20.4 minutes.

slightly, it is generally accepted that a RATIO value above 1.5 is clearly abnormal.

Less sophisticated but technically much simpler to perform than dynamic scans are static acquisitions. In this procedure, the time-course of activity is not measured but only an integral (sum) image of tissue activity of a certain period after tracer injection is acquired. By then it is assumed that the tracer has reached a state of pseudo-equilibrium so that the tissue activity-concentration ratio can be used as an apparent volume of distribution ratio [33] (Figure 6).

\section{Statistical parametric mapping}

The statistical parametric mapping (SPM) method of analysis is an approach used to localise significant changes in brain physiology or pharmacology. This localisation is achieved by applying the general linear model to all independent voxels and creating an image of a statistic. SPM refers to the construction of spatially extended statistical processes to test hypotheses about regionally specific effects. SPMs are image processes with voxel values that are, under the null hypothesis, distributed according to a known probability density function (usually Gaussian). These statistical parametric maps are three-dimensional projections of statistical functions that are used to characterise significant regional brain differences in imaging parameters. The theory of Gaussian fields is used to provide $P$ values that are corrected for the brain volume analysed $[34,35]$.
To implement voxel-based analysis of imaging data, the data from different subjects must derive from homologous parts of the brain. Spatial transformations are therefore applied that move and warp the images such that they all conform (approximately) to some standard brain. This normalisation facilitates intersubject averaging. The normalising transformations can be computed on the basis of the PET data themselves on the basis of co-registered high-resolution anatomical MRI. Convolving the data with a smoothing kernel has several important objectives. First, it generally increases the signal relative to noise. Second, convolving with a Gaussian kernel conditions the data to conform more closely to a Gaussian field model, even though this reduces spatial resolution.

The aim of the analysis is to identify areas of cerebral $\left[{ }^{11} \mathrm{C}\right] \mathrm{PIB}$ binding that were significantly different in patients compared with the controls. Significant differences between patients and control subjects were estimated according to the general linear model at each and every voxel [36]. Comparison between patients and controls as groups was performed without using analysis of covariance. Linear contrasts were used to test the hypotheses for specific focal effects. The resulting set of voxel values for each contrast constitutes a statistical parametric map of the $t$ statistic SPM $[t]$.

Spatially normalised RATIO images could be interrogated using different thresholds. Here we have used a threshold of $P<0.00001$ with an extent threshold of 200 


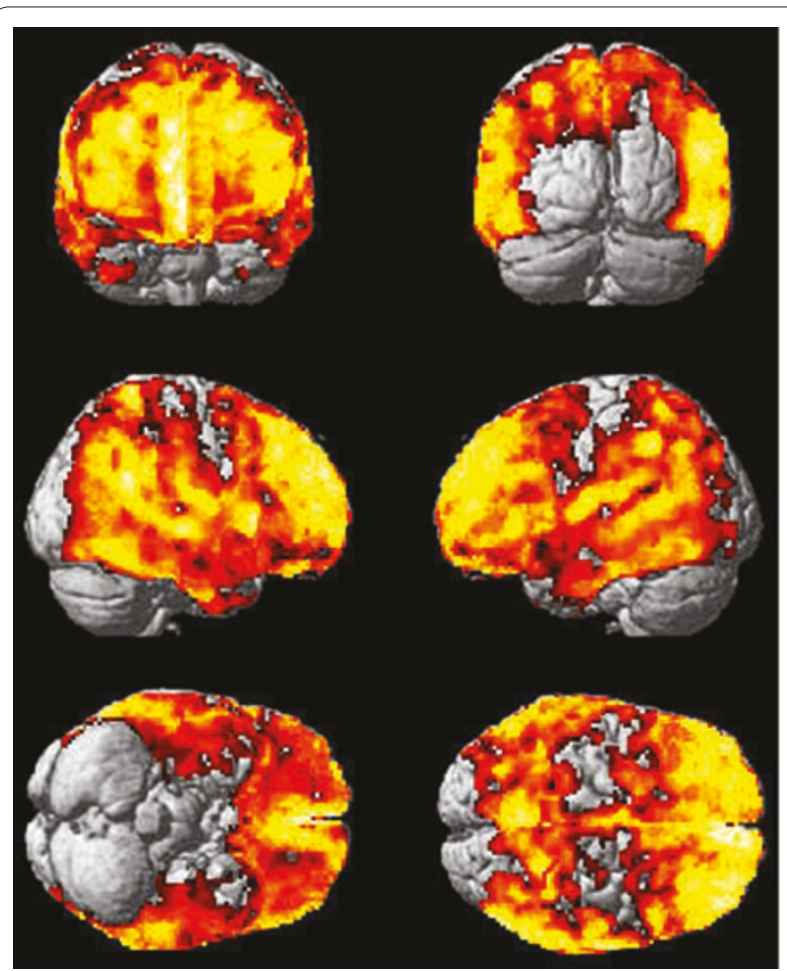

Figure 7. Statistical parametric map. Statistical parametric mapping of $\left[{ }^{11} \mathrm{C}\right]$ Pittsburgh Compound $\mathrm{B}\left(\left[{ }^{1} \mathrm{C}\right] \mathrm{PIB}\right)$ in 12 Alzheimer's disease patients against 10 control subjects. Significantly increased $\left[{ }^{11} \mathrm{C}\right] \mathrm{PIB}$ uptake in the frontal, temporal, parietal and occipital cortices at a voxel threshold of $P<0.00001$ and an extent threshold of 200 voxels.

voxels to detect significant change without applying analysis of covariance or proportional scaling. Figure 7 shows $\left[{ }^{11} \mathrm{C}\right] \mathrm{PIB}$ uptake was high in $\mathrm{AD}$ patients compared with the healthy control subjects in frontal, temporal, parietal and occipital cortices. SPM was not able to interrogate the parametric images at a lower threshold for significance. $\left[{ }^{11} \mathrm{C}\right] \mathrm{PIB}$ also showed a significant increase in mild cognitive impairment subjects, as $60 \%$ of these patients had significantly increased levels compared with those of AD.

\section{Newer amyloid tracers}

A fluorinated derivative of PIB, $\left[{ }^{18} \mathrm{~F}\right]$ flutemetamol, is now being developed and studied [37]. Since the half-life of this compound is considerably higher than carbon-11 compounds, a cyclotron is not necessary for routine studies as this could be manufactured at one site and could be distributed. $\left.{ }^{18} \mathrm{~F}\right]$ Flutemetamol is analysed using the target to cerebellar ratio similar to $\left[{ }^{11} \mathrm{C}\right] \mathrm{PIB}$ [38]. Other fluorinated compounds widely tested for amyloid imaging include $\left[{ }^{18} \mathrm{~F}\right] \mathrm{AV}-45[39,40]$ and florbetaben $[41]$. A head-to-head comparison of $\left[{ }^{18} \mathrm{~F}\right] \mathrm{AV}-45$ against $\left[{ }^{11} \mathrm{C}\right]$ PIB is now underway. Several other imaging agents are also in development.
This article is part of a review series on Amyloid Imaging. Other articles in the series can be found online at http://alzres.com/series/ amyloidimaging

\section{Abbreviations}

$A \beta, \beta$-amyloid protein; $A D$, Alzheimer's disease; [ $\left.{ }^{18} \mathrm{~F}\right] \mathrm{AV}$-45, florbetapir; HPLC, high-performance liquid chromatography; MRI, magnetic resonance imaging: PET, positron emission tomography; PIB, Pittsburgh Compound B; SPM, statistical parametric mapping; VOI, volume of interest.

\section{Competing interests}

DJB is the chief medical officer for GE Healthcare, who hold the commercial licence for $\left.{ }^{111}\right]$ PIB and $\left[{ }^{[8} \mathrm{F}\right]$ flutemetamol. The other authors declare no competing interests.

\section{Author details}

'Medical Research Council Clinical Sciences Centre and Division of Neuroscience, Imperial College London, Cyclotron Building, Hammersmith Hospital, Du Cane Road, London W12 0NN, UK. ${ }^{2}$ Wolfson Molecular Imaging Centre, University of Manchester, 27 Palatine Road, Withington, Manchester M20 3L, UK.

Published: 31 August 2011

\section{References}

1. McKhann G, Drachman D, Folstein M, Katzman R, Price D, Stadlan EM: Clinical diagnosis of Alzheimer's disease: report of the NINCDS-ADRDA Work Group under the auspices of Department of Health and Human Services Task Force on Alzheimer's Disease. Neurology 1984, 34:939-944.

2. American Psychiatric Association: Diagnostic and Statistical Manual of Mental Disorders. 4th edition. Arlington, VA: American Psychiatric Association.

3. Dubois B, Feldman HH, Jacova C, Cummings JL, Dekosky ST, BarbergerGateau P, Delacourte A, Frisoni G, Fox NC, Galasko D, Gauthier S, Hampel H, Jicha GA, Meguro K, O'Brien J, Pasquier F, Robert P, Rossor M, Salloway S, Sarazin M, de Souza LC, Stern Y, Visser PJ, Scheltens P: Revising the definition of Alzheimer's disease: a new lexicon. Lancet Neurol 2007, 9:1118-1127.

4. Greene JD, Baddeley AD, Hodges JR: Analysis of the episodic memory deficit in early Alzheimer's disease: evidence from the doors and people test. Neuropsychologia 1996, 34:537-551.

5. Price BH, Gurvit H, Weintraub S, Geula C, Leimkuhler E, Mesulam M: Neuropsychological patterns and language deficits in 20 consecutive cases of autopsy-confirmed Alzheimer's disease. Arch Neurol 1993, 50:931-937.

6. Esteban-Santillan C, Praditsuwan R, Ueda H, Geldmacher DS: Clock drawing test in very mild Alzheimer's disease. J Am Geriatr Soc 1998, 46:1 266-1269.

7. Erkinjuntti T, Rockwood K: Vascular dementia. Semin Clin Neuropsychiatry 2003, 8:37-45.

8. Dickson DW: The pathogenesis of senile plaques. J Neuropathol Exp Neurol 1997, 56:321-339.

9. Silverman DH, Small GW, Chang CY, Lu CS, Kung De Aburto MA, Chen W, Czernin J, Rapoport SI, Pietrini P, Alexander GE, Schapiro MB, Jagust WJ, Hoffman JM, Welsh-Bohmer KA, Alavi A, Clark CM, Salmon E, de Leon MJ, Mielke R, Cummings JL, Kowell AP, Gambhir SS, Hoh CK, Phelps ME: Positron emission tomography in evaluation of dementia: regional brain metabolism and long-term outcome. JAMA 2001, 286:2120-2127.

10. Klunk WE, Wang Y, Huang GF, Debnath ML, Holt DP, Mathis CA: Uncharged thioflavin-T derivatives bind to amyloid-beta protein with high affinity and readily enter the brain. Life Sci 2001, 69:1471-1484.

11. Mathis CA, Wang Y, Holt DP, Huang GF, Debnath ML, Klunk WE: Synthesis and evaluation of ${ }^{11} \mathrm{C}$-labeled 6-substituted 2-arylbenzothiazoles as amyloid imaging agents. J Med Chem 2003, 46:2740-2754.

12. Mathis CA, Bacskai BJ, Kajdasz ST, McLellan ME, Frosch MP, Hyman BT, Holt DP, Wang Y, Huang GF, Debnath ML, Klunk WE: A lipophilic thioflavin-T derivative for positron emission tomography (PET) imaging of amyloid in brain. Bioorg Med Chem Lett 2002, 12:295-298.

13. Klunk WE, Engler $H$, Nordberg A, Wang $Y$, Blomqvist $G$, Holt DP, Bergstrom $M$, Savitcheva I, Huang GF, Estrada S, Ausen B, Debnath ML, Barletta J, Price JC, Sandell J, Lopresti BJ, Wall A, Koivisto P, Antoni G, Mathis CA, Langstrom B: Imaging brain amyloid in Alzheimer's disease with Pittsburgh CompoundB. Ann Neurol 2004, 55:306-319. 
14. Rowe CC, Ng S, Ackermann U, Gong SJ, Pike K, Savage G, Cowie TF, Dickinson KL, Maruff P, Darby D, Smith C, Woodward M, Merory J, Tochon-Danguy H, O'Keefe G, Klunk WE, Mathis CA, Price JC, Masters CL, Villemagne VL: Imaging $\beta$-amyloid burden in aging and dementia. Neurology 2007, 68:1718-1725.

15. Edison P, Rowe CC, Rinne JO, Ng S, Ahmed I, Kemppainen N, Villemagne VL, O'Keefe G, Nagren K, Chaudhury KR, Masters CL, Brooks DJ: Amyloid load in Parkinson's disease dementia and Lewy Body dementia measured with $\left[{ }^{11}\right.$ C]PIB-PET. J Neurol Neurosurg Psychiatry 2008, 79:1331-1338.

16. Nordberg A: Amyloid imaging in Alzheimer's disease. Curr Opin Neurol 2007 20:398-402.

17. Ikonomovic MD, Klunk WE, Abrahamson EE, Mathis CA, Price JC, Tsopelas ND, Lopresti BJ, Ziolko S, Bi W, Paljug WR, Debnath ML, Hope CE, Isanski BA, Hamilton RL, DeKosky ST: Post-mortem correlates of in vivo PiB-PET amyloid imaging in a typical case of Alzheimer's disease. Brain 2008, 131 (Pt 6):1630-1645.

18. Natterer F, Wubbeling F: Mathematical Methods in Image Reconstruction. Series: Monographs on Mathematical Modeling and Computation. Society for Industrial and Applied Mathematics: 2001.

19. Mintun MA, Raichle ME, Kilbourn MR, Wooten GF, Welch MJ: A quantitative model for the in vivo assessment of drug binding sites with positron emission tomography. Ann Neurol 1984, 15:217-227.

20. Choi SR, Golding G, Zhuang Z, Zhang W, Lim N, Hefti F, Benedum TE, Kilbourn MR, Skovronsky D, Kung HF: Preclinical properties of 18F-AV-45: a PET agent for A $\beta$ plaques in the brain. J Nucl Med 2009, 50:1887-1894.

21. Innis RB, Cunningham VJ, Delforge J, Fujita M, Gjedde A, Gunn RN, Holden J, Houle S, Huang SC, Ichise M, lida H, Ito H, Kimura Y, Koeppe RA, Knudsen GM, Knuuti J, Lammertsma AA, Laruelle M, Logan J, Maguire RP, Mintun MA, Morris ED, Parsey R, Price JC, Slifstein M, Sossi V, Suhara T, Votaw JR, Wong DF, Carson RE: Consensus nomenclature for in vivo imaging of reversibly binding radioligands. J Cereb Blood Flow Metab 2007, 27:1533-1539.

22. Blomquist $G$, Engler $H$, Nordberg A, Ringheim A, Wall A, Forsberg A, Estrada $S$, Frandberg P, Antoni G, Langstrom B: Unidirectional influx and net accumulation of PIB. Open Neuroimaging J 2008, 2:114-125.

23. Blomqvist $\mathrm{G}$ : On the construction of functional maps in positron emission tomography. J Cereb Blood Flow Metab 1984, 4:629-632.

24. Gunn RN, Gunn SR, Cunningham VJ: Positron emission tomography compartmental models. J Cereb Blood Flow Metab 2001, 21:635-652.

25. Logan J, Fowler JS, Volkow ND, Wolf AP, Dewey SL, Schlyer DJ, MacGregor RR Hitzemann R, Bendriem B, Gatley SJ, et al.: Graphical analysis of reversible radioligand binding from time-activity measurements applied to $\left[N-{ }^{11} \mathrm{C}\right.$ methyl]-(-)-cocaine PET studies in human subjects. J Cereb Blood Flow Metab 1990, 10:740-747.

26. Patlak CS, Blasberg RG: Graphical evaluation of blood-to-brain transfer constants from multiple-time uptake data. Generalizations. J Cereb Blood Flow Metab 1985, 5:584-590.

27. Patlak CS, Blasberg RG, Fenstermacher JD: Graphical evaluation of blood-tobrain transfer constants from multiple-time uptake data. J Cereb Blood Flow Metab 1983, 3:1-7.

28. Cunningham VJ, Jones T: Spectral analysis of dynamic PET studies. J Cereb Blood Flow Metab 1993, 13:15-23.

29. Lammertsma AA, Bench CJ, Hume SP, Osman S, Gunn K, Brooks DJ, Frackowiak RS: Comparison of methods for analysis of clinical $\left[{ }^{11} \mathrm{C}\right]$ raclopride studies. J Cereb Blood Flow Metab 1996, 16:42-52. 30. Lammertsma AA, Hume SP: Simplified reference tissue model for PET receptor studies. Neuroimage 1996, 4(3 Pt 1):153-158.

31. Edison P, Archer HA, Hinz R, Hammers A, Pavese N, Tai YF, Hotton G, Cutler D, Fox N, Kennedy A, Rossor M, Brooks DJ: Amyloid, hypometabolism, and cognition in Alzheimer disease: an $\left[{ }^{11} \mathrm{C}\right] \mathrm{PIB}$ and $\left[{ }^{18} \mathrm{~F}\right] \mathrm{FDG}$ PET study. Neurology 2007, 68:501-508

32. Villemagne VL, Pike KE, Chetelat $G$, Ellis KA, Mulligan RS, Bourgeat $P$, Ackermann U, Jones G, Szoeke C, Salvado O, Martins R, O'Keefe G, Mathis CA Klunk WE, Ames D, Masters CL, Rowe CC: Longitudinal assessment of A $\beta$ and cognition in aging and Alzheimer disease. Ann Neurol 2011, 69:181-192.

33. Carson RE, Channing MA, Blasberg RG, Dunn BB, Cohen RM, Rice KC, Herscovitch P: Comparison of bolus and infusion methods for receptor quantitation: application to $\left[{ }^{18} \mathrm{~F}\right]$ cyclofoxy and positron emission tomography. J Cereb Blood Flow Metab 1993, 13:24-42.

34. Friston KJ, Frith CD, Liddle PF, Frackowiak RS: Plastic transformation of PET images. J Comput Assist Tomogr 1991, 15:634-639.

35. Worsley KJ, Evans AC, Marrett S, Neelin P: A three-dimensional statistical analysis for CBF activation studies in human brain. J Cereb Blood Flow Metab 1992, 12:900-918.

36. Friston KJ, Frith CD, Liddle PF, Dolan RJ, Lammertsma AA, Frackowiak RS: The relationship between global and local changes in PET scans. J Cereb Blood Flow Metab 1990, 10:458-466.

37. Nelissen N, Van Laere K, Thurfell L, Owenius R, Vandenbulcke M, Koole M, Bormans G, Brooks DJ, Vandenberghe R: Phase 1 study of the Pittsburgh compound $\mathrm{B}$ derivative ${ }^{18} \mathrm{~F}$-flutemetamol in healthy volunteers and patients with probable Alzheimer disease. J Nucl Med 2009, 50:1251-1259.

38. Vandenberghe R, Van Laere K, Ivanoiu A, Salmon E, Bastin C, Triau E, Hasselbalch S, Law I, Andersen A, Korner A, Minthon L, Garraux G, Nelissen N, Bormans G, Buckley C, Owenius R, Thurfjell L, Farrar G, Brooks DJ: ${ }^{18} \mathrm{~F}$ flutemetamol amyloid imaging in Alzheimer disease and mild cognitive impairment: a phase 2 trial. Ann Neurol 2010, 68:319-329.

39. Clark CM, Schneider JA, Bedell BJ, Beach TG, Bilker WB, Mintun MA, Pontecorvo MJ, Hefti F, Carpenter AP, Flitter ML, Krautkramer MJ, Kung HF, Coleman RE, Doraiswamy PM, Fleisher AS, Sabbagh MN, Sadowsky CH, Reiman EP, Zehntner SP, Skovronsky DM: Use of florbetapir-PET for imaging $\beta$-amyloid pathology. JAMA 2011, 305:275-283.

40. Okamura $\mathrm{N}$, Yanai K: Florbetapir $\left({ }^{18} \mathrm{~F}\right)$, a PET imaging agent that binds to amyloid plaques for the potential detection of Alzheimer's disease. IDrugs 2010, 13:890-899.

41. Barthel H, Gertz HJ, Dresel S, Peters $O$, Bartenstein P, Buerger K, Hiemeyer F, Wittemer-Rump SM, Seibyl J, Reininger C, Sabri O: Cerebral amyloid-beta PET with florbetaben $\left({ }^{18} \mathrm{~F}\right)$ in patients with Alzheimer's disease and healthy controls: a multicentre phase 2 diagnostic study. Lancet Neurol 2011, 10:424-435.

42. Edison P, Brooks DJ, Turkheimer FE, Archer HA, Hinz R: Strategies for the generation of parametric images of $\left[{ }^{11} \mathrm{C}\right] \mathrm{PIB}$ with plasma input functions considering discriminations and reproducibility. Neuroimage 2009, 48:329-338.

doi:10.1186/alzrt87

Cite this article as: Edison P, et al:: Technical aspects of amyloid imaging for Alzheimer's disease. Alzheimer's Research \& Therapy 2011, 3:25. 